\title{
Cetuximab enhances cisplatin-induced endoplasmic reticulum stress-associated apoptosis in laryngeal squamous cell carcinoma cells by inhibiting expression of TXNDC5
}

\author{
FUSEN PENG ${ }^{1,2}$, HAILIN ZHANG ${ }^{3}$, YOUHONG DU ${ }^{2}$ and PINGQING TAN ${ }^{3}$ \\ ${ }^{1}$ Department of Otolaryngology Head and Neck Surgery, Xiangya Hospital, Central South University, Changsha, Hunan 410008; \\ ${ }^{2}$ Department of Otolaryngology Head and Neck Surgery, Loudi Central Hospital, Loudi, Hunan 417000; \\ ${ }^{3}$ Department of Head and Neck Surgery, Hunan Tumor Hospital, Changsha, Hunan 410013, P.R. China
}

Received May 26, 2016; Accepted April 13, 2017

DOI: $10.3892 / \mathrm{mmr} .2018 .8376$

\begin{abstract}
Cisplatin and cetuximab, an anti-epidermal growth factor receptor (EGFR) monoclonal humanized antibody, have been used for treatment of laryngeal squamous cell carcinoma (LSCC). It has been demonstrated that cisplatin and inhibition of EGFR signaling may induce endoplasmic reticulum (ER) stress-associated apoptosis. However, ER protein thioredoxin domain-containing protein 5 (TXNDC5) reportedly protects cells from ER stress-associated apoptosis. The present study investigated the interaction between cisplatin, cetuximab and TXNDC5 on ER stress-associated apoptosis in LSCC cells. AMC-HN-8 human LSCC cells with or without TXNDC5 overexpression or knockdown were treated with cisplatin $(5,10$, 20 and $40 \mu \mathrm{M})$ and/or cetuximab (10, 50, 100 and $150 \mu \mathrm{g} / \mathrm{ml})$, for $12,24,36$ and $48 \mathrm{~h}$. Cisplatin and cetuximab concentrationand time-dependently increased and decreased the expression of TXNDC5 in AMC-HN-8 cells, respectively. Knockdown of TXNDC5 markedly augmented cisplatin-induced levels of CCAAT/enhancer-binding protein homologous protein (CHOP), caspase-3 activity and apoptosis; while overexpression of TXNDC5 largely eliminated cetuximab-induced levels of CHOP, caspase-3 activity and apoptosis. Cisplatin and cetuximab demonstrated a combinatorial effect on increasing the levels of CHOP, caspase-3 activity and apoptosis, which was largely eliminated by overexpression of TXNDC5 or a reactive oxygen species (ROS) scavenger/antagonist. In addition, promoter/luciferase reporter assays revealed that cisplatin and cetuximab regulated the expression of TXNDC5 at the gene transcription/promoter level. In conclusion, the
\end{abstract}

Correspondence to: Dr Hailin Zhang, Department of Head and Neck Surgery, Hunan Tumor Hospital, 582 Xianjiahu Road, Changsha, Hunan 410013, P.R. China

E-mail: zhangyang770@yahoo.com

Key words: cetuximab, cisplatin, laryngeal squamous cell carcinoma, endoplasmic reticulum stress, thioredoxin domain-containing protein 5 , apoptosis findings suggested that ER stress-associated apoptosis is a major mechanism underlying the apoptotic effect of cisplatin and cetuximab on LSCC cells; cetuximab enhanced cisplatin-induced ER stress-associated apoptosis in LSCC cells largely by inhibiting the expression of TXNDC5 and thereby increasing ROS production; cisplatin and cetuximab had stimulatory and inhibitory effects on the TXNDC5 gene promoter, respectively. The present study offered novel insights into the pharmacological effects of cisplatin and cetuximab on LSCC. It also suggested that TXNDC5 may be a potential therapeutic target for LSCC.

\section{Introduction}

Laryngeal squamous cell carcinoma (LSCC), which accounts for $\sim 14 \%$ of head and neck squamous cell carcinomas (SCCs) (1), is one of the most common carcinomas of the head and neck (1). Key features of LSCC include rapid progression, aggressive behavior, resistance to chemotherapy and poor prognosis $(2,3)$. Patients with advanced LSCC are typically treated with a combination of surgery, chemotherapy and radiation therapy (4). Despite advances in treatment, the survival of patients with LSCC remains low, primarily due to its resistance to anticancer drugs $(2,3)$. Therefore, it is imperative to identify novel methods to improve therapeutic efficacy for this disease.

Overexpression of epidermal growth factor receptor (EGFR) has been associated with tumor progression and resistance to chemotherapy and radiotherapy (5). EGFR and its ligands are overexpressed in head and neck SCCs including LSCC (5). Cetuximab, an anti-EGFR monoclonal humanized antibody, has been proved clinically effective in patients with recurrent or metastatic head and neck SCCs in combination with cisplatin-based chemotherapy $(5,6)$. A recent in vitro study has demonstrated that cetuximab increases the therapeutic effect of cisplatin in LSCC cells (5).

As the most commonly used chemotherapeutic agent for the treatment of solid tumors, cisplatin has been proven effective for treatment of LSCC (7). However, the efficacy of cisplatin diminishes when LSCC develops resistance to it during the treatment process (7). It has been demonstrated that cisplatin 
has effects on multiple cellular targets in tumor cells in addition to nuclear DNA (8-10). Previous studies have revealed that cisplatin induces endoplasmic reticulum (ER) stress (11-13). ER stress-associated apoptosis is hypothesized to be a major cisplatin-induced pathway, which contributes to cisplatin cytotoxicity and is also involved in cisplatin resistance (14). Recent studies have suggested that EGFR signaling is also involved in ER stress-associated apoptosis $(15,16)$. Miao et al (15) demonstrated that EGFR signaling protected cardiomyocytes from ER stress-associated apoptosis. However, Hong et al (16) demonstrated that inhibiting EGFR signaling triggered ER stress, which resulted in ER-mediated cell death.

ER is an essential subcellular compartment responsible for the synthesis and folding of proteins (17). Various physiological and pathological conditions may lead to ER stress, which results in an accumulation of unfolded or misfolded proteins in the ER lumen $(18,19)$. This cellular stress subsequently causes an activation of the unfolded protein response, which induces the expression of chaperones and proteins involved in the recovery process (20). Moderate ER stress can be resolved and ER homeostasis restored to maintain cell survival, whereas severe and prolonged ER stress may induce cell apoptosis by activating downstream apoptotic signaling pathways (20). A decisive factor in this process is CCAAT/enhancer-binding protein homologous protein (CHOP), also known as growth arrest and DNA damage inducible gene (GADD153) (21). CHOP exhibits pro-apoptotic activity and is critical for triggering apoptosis in response to ER stress (22). Increased expression of CHOP activates caspases, integrates mitochondrial events and amplifies the death signal (21).

Thioredoxin domain-containing protein 5 (TXNDC5), a member of the disulfide isomerase family, is primarily expressed in the ER (23). It has been demonstrated that TXNDC5 protects cells from ER stress-induced apoptosis $(24,25)$ by facilitating proteins to fold correctly via formation of disulfide bonds through its thioredoxin domains (26).

The present study for the first time, to the best of the authors' knowledge, investigated the interaction among cisplatin, cetuximab and TXNDC5 in ER stress-associated apoptosis in LSCC cells.

\section{Materials and methods}

Cell culture and treatments. The AMC-HN-8 human LSCC cell line was purchased from the Shanghai Institute of the Chinese Academy of Science (Shanghai, China), and cultured in RPMI 1640 media supplemented with $10 \%$ fetal bovine serum and $100 \mu \mathrm{M}$ penicillin and streptomycin (Thermo Fisher Scientific, Inc., Waltham, MA, USA) in a humidified atmosphere containing $5 \% \mathrm{CO}_{2}$ at $37^{\circ} \mathrm{C}$. The cells were treated with cisplatin (Sigma-Aldrich; Merck KGaA, Darmstadt, Germany) at 5, 10, 20 and $40 \mu \mathrm{M}$ and/or cetuximab (Merck KGaA) at $10,50,100$ and $150 \mu \mathrm{g} / \mathrm{ml}$ for $12,24,36$ and $48 \mathrm{~h}$, in the presence or absence of $10 \mathrm{mM}$ reactive oxygen species (ROS) scavenger/antagonist N-acetylcysteine (NAC; Sigma-Aldrich; Merck KGaA). For TXNDC5 knockdown, AMC-HN-8 cells were transduced with human ERp46/TXNDC5 lentiviral particles (sc-60601-V; Santa Cruz Biotechnology, Inc., Dallas, TX, USA), with cells transduced with control short hairpin RNA (shRNA) lentiviral particles (sc-108080; Santa Cruz
Biotechnology, Inc.) as a control. For TXNDC5 overexpression, human full length TXNDC5 cDNA clone (SC109657) was purchased from Origene Technologies, Inc. (Beijing, China) and subcloned into pcDNA 3.1 expression vector (V79020; Thermo Fisher Scientific, Inc.); then AMC-HN-8 cells were transfected with the TXNDC5-expressing vector using Lipofectamine 3000 transfection reagent (L3000008; Thermo Fisher Scientific, Inc.), according to the manufacturer's protocol. Empty expression vector was used as the control. The cells were subject to subsequent experiments $24 \mathrm{~h}$ following transduction/transfection.

Real-time reverse transcription-quantitative polymerase chain reaction $(R T-q P C R)$. RNA was prepared from AMC-HN-8 cells using TRIzol reagent (Thermo Fisher Scientific, Inc.) followed by purification with TURBO DNA-free System (Ambion, Austin, TX, USA). cDNA was synthesized using SuperScript II reverse transcriptase (Thermo Fisher Scientific, Inc.) and random hexamer primers (Thermo Fisher Scientific, Inc.). RT-qPCR was performed using an ABI-PRISM 7700 Sequence Detection System (Applied Biosystems; Thermo Fisher Scientific, Inc.) and the fluorescent dye SYBR Green Master Mix (Thermo Fisher Scientific, Inc.), according to the manufacturer's protocol. The primers used were as follows: Forward, 5'-GGGTCAAGATCGCCGAAGTA-3' and reverse, 5'GCCTCCACTGTGCTCACTGA3' for TXNDC5; and forward, 5'CCCTGTAATTGGAATGAGTCCAC3' and reverse, 5'GCTGGAATTACCGCGGCT3' for $18 \mathrm{~S}$ rRNA. The PCR amplification condition was: Initial denaturation for $20 \mathrm{sec}$ at $95^{\circ} \mathrm{C}, 40$ cycles of denaturation for $3 \mathrm{sec}$ at $95^{\circ} \mathrm{C}$, annealing for $30 \mathrm{sec}$ at $60^{\circ} \mathrm{C}$. Relative quantification of the TXNDC5 expression level was determined using the $2^{-\Delta \Delta C q}$ method (27) and normalized against that of 18S rRNA in the same sample. Each experiment was repeated three independent times in duplicate.

Western blot analysis. Whole cell lysates were extracted by incubating AMC-HN-8 cells with lysis buffer $[50 \mathrm{mM}$ Tris- $\mathrm{HCl}$ ( $\mathrm{pH} 7.2$ ), $150 \mathrm{mM} \mathrm{NaCl}, 1 \%$ (v/v) Triton X-100, $1 \mathrm{mM}$ sodium orthovanadate, $50 \mathrm{mM}$ sodium pyrophosphate, $100 \mathrm{mM}$ sodium fluoride, $0.01 \%$ (v/v) aprotinin, $4 \mu \mathrm{g} / \mathrm{ml}$ pepstatin A, $10 \mu \mathrm{g} / \mathrm{ml}$ leupeptin and $1 \mathrm{mM}$ phenylmethanesulfonyl fluoride; all Sigma-Aldrich; Merck KGaA] on ice for $30 \mathrm{~min}$ and removing cell debris by centrifugation at $2,000 \mathrm{x} \mathrm{g}$ for $15 \mathrm{~min}$ at $4^{\circ} \mathrm{C}$. For the detection of nuclear receptor subfamily 4 group A member 1 (NR4A1), nuclear extracts were prepared as previously described (28). Equal amount of proteins $(7 \mu \mathrm{g})$ for each sample were separated by $10 \%$ SDS-PAGE and blotted onto a polyvinylidene difluoride microporous membrane (EMD Millipore, Billerica, MA, USA). The membranes were blocked with 5\% skimmed milk powder in TBS containing 0.1\% Tween-20 (SRE0031; Sigma-Aldrich; Merck KGaA) for $2 \mathrm{~h}$ at room temperature, and incubated for $1 \mathrm{~h}$ at room temperature with a 1:1,000 dilution of goat anti-human ERp46/TXNDC5 polyclonal antibody (sc-49660), mouse anti-mouse GADD153/CHOP monoclonal antibody (sc-7351), rabbit anti-human cleaved caspase-3 p11 polyclonal antibody (sc-22171-R), mouse anti-human $\beta$-actin monoclonal antibody (sc-130301), mouse anti-human NR4A1/Nur77 monoclonal antibody (sc-365113), or goat 
anti-human histone $\mathrm{H} 3$ polyclonal antibody (sc-8654; all Santa Cruz Biotechnology, Inc.). Membranes were subsequently washed in TBST (Sigma-Aldrich; Merck KGaA) for 5 min three times, and probed using bovine anti-goat (sc-2378), bovine anti-mouse (sc-2371) or bovine anti-rabbit (sc-2370; all Santa Cruz Biotechnology, Inc.) horseradish peroxidase-conjugated secondary antibodies at a 1:5,000 dilution for $1 \mathrm{~h}$ at room temperature. Protein bands were visualized by enhanced chemiluminescence (GE Healthcare Life Sciences, Little Chalfont, UK) using the ChemiDoc Touch Imaging system (Bio-Rad Laboratories, Inc., Hercules, CA, USA) and Image Lab Touch software version 4.1 (Bio-Rad Laboratories, Inc.) for image acquisition and densitometric analysis. Three independent experiments were performed.

Intracellular ROS detection. ROS were measured using the Dichlorodihydrofluorescein Diacetate (DCFDA) Cellular Reactive Oxygen Species Detection Assay kit (ab113851; Abcam, Cambridge, UK), according to the manufacturer's protocol. Cells were plated at $7 \times 10^{4}$ cells/well in black 96-well plates and incubated with $25 \mu \mathrm{M}$ DCFDA for $45 \mathrm{~min}$ at $37^{\circ} \mathrm{C}$. Fluorescence was detected using a Victor3 1420 Multilabel Counter (PerkinElmer, Inc., Shanghai, China).

Caspase-3 activity assay. The activity of caspase-3 was determined using a colorimetric Caspase-3 Assay kit (ab39401; Abcam, Cambridge, MA, USA). The assays were performed in 96-well plates by incubating $20 \mu \mathrm{l}$ cell lysate protein/sample in $70 \mu \mathrm{l}$ reaction buffer [1\% NP-40, $20 \mathrm{mM}$ Tris- $\mathrm{HCl}(\mathrm{pH} 7.5)$, $137 \mathrm{mM} \mathrm{Nad}$ and $10 \%$ glycerol] containing $10 \mu \mathrm{l}$ caspase-3 substrate $(2 \mathrm{mM})$. The lysates were subsequently incubated at $37^{\circ} \mathrm{C}$ for $6 \mathrm{~h}$, following which the samples were assayed using an iMark Microplate Absorbance Reader (1681130; Bio-Rad Laboratories, Inc.) at $405 \mathrm{~nm}$. Each experiment was repeated three independent times in duplicate.

Cellular apoptosis assay. AMC-HN-8 cells with or without TXNDC5 knockdown or overexpression were cultured at $7 \times 10^{4}$ cells/well in 96-well tissue culture plates in the presence of cisplatin $(40 \mu \mathrm{M})$ and/or cetuximab $(150 \mu \mathrm{g} / \mathrm{ml})$ for $48 \mathrm{~h}$ at $37^{\circ} \mathrm{C}$. Cellular apoptosis was measured with a microplate reader-based TiterTACS in situ apoptosis detection kit (4822-96-K; R\&D systems, Inc., Minneapolis, MN, USA), according to manufacturer's protocol. Each experiment was repeated three independent times in duplicate.

Luciferase reporter assay. AMC-HN-8 cells were transfected with a commercially available human TXNDC5 gene promoter/pLightSwitch_Prom luciferase reporter (S709642; SwitchGear Genomics, Menlo Park, CA, USA) using Lipofectamine 3000 transfection reagent (Thermo Fisher Scientific, Inc.) for $24 \mathrm{~h}$ at $37^{\circ} \mathrm{C}$, and subsequently treated with cisplatin (Sigma-Aldrich; Merck KGaA) at 5, 10, 20 and $40 \mu \mathrm{M}$ and/or cetuximab (Merck KGaA) at 10, 50, 100 and $150 \mu \mathrm{g} / \mathrm{ml}$ for $48 \mathrm{~h} 37^{\circ} \mathrm{C}$. Luciferase assays were performed with the LightSwitch Luciferase Assay kit (LS010; SwitchGear Genomics) according to the manufacturer's protocol. Plasmid PRL-CMV (Promega Corporation, Madison, WI, USA) encoding Renilla luciferase (at 1/5 molar ratio to the reporter plasmid) was co-transfected with the reporter plasmid in each transfection as an internal control for data normalization. Each experiment was repeated three independent times in duplicate.

Statistical analysis. Statistical analyses were performed with SPSS software version 10.0 (SPSS Inc., Chicago, IL, USA). All data values were expressed as the mean \pm standard deviation. Comparisons of means among multiple groups were performed using one-way analysis of variance followed by post hoc pairwise comparisons using Tukey's test. $\mathrm{P}<0.05$ was considered to indicate a statistically significant difference.

\section{Results}

Cisplatin and cetuximab increase and decrease the expression of TXNDC5 in human LSCC cells, respectively. To examine the effects of cisplatin and cetuximab on the expression of TXNDC5 in LSCC cells, AMC-HN-8 human LSCC cells were treated with cisplatin $(5,10,20$ and $40 \mu \mathrm{M})$ or cetuximab $(10,50,100$ and $150 \mu \mathrm{g} / \mathrm{ml})$ for $12,24,36$ and $48 \mathrm{~h}$. As demonstrated in Table I, cisplatin concentration- and time-dependently increased the mRNA level of TXNDC5 in AMC-HN-8 cells, until it reached a plateau at $20-40 \mu \mathrm{M}$ following 36-48 h of treatment. As demonstrated in Table II, cetuximab concentration- and time-dependently decreased the mRNA level of TXNDC5 in AMC-HN-8 cells, until it reached a plateau at $100-150 \mu \mathrm{g} / \mathrm{ml}$ following $36-48 \mathrm{~h}$ of treatment. Western blot analyses confirmed that in AMC-HN-8 cells under $48 \mathrm{~h}$ of treatment, cisplatin and cetuximab concentration-dependently increased and decreased the protein levels of TXNDC5 until reaching a plateau at 20-40 $\mu \mathrm{M}$ and $100-150 \mu \mathrm{g} / \mathrm{ml}$, respectively (Fig. 1).

Cetuximab enhances cisplatin-induced ER stress-associated apoptosis in LSCC cells by inhibiting expression of TXNDC5. It has been reported that cisplatin induces ER stress-associated apoptosis $(20,21)$, while TXNDC5 has been demonstrated to protect cells from ER stress-induced apoptosis $(24,25)$. Recent studies have suggested that EGFR signaling is also involved in ER stress-associated apoptosis $(15,16)$. To investigate the functional role of TXNDC5 in the effects of cisplatin and cetuximab on ER stress in LSCC cells, TXNDC5 was overexpressed and knocked down in AMC-HN-8 cells, respectively. As demonstrated in Fig. 2, compared with the controls, TXNDC5 was successfully overexpressed $>3$-fold and knocked down by $>80 \%$ in AMC-HN-8 cells. As demonstrated in Fig. 3, compared with the control, cisplatin $(40 \mu \mathrm{M})$ increased the expression of TXNDC5 by $\sim 3$-fold, which was completely eliminated by knocking down TXNDC5; however, cetuximab $(150 \mu \mathrm{g} / \mathrm{ml})$ decreased the expression of TXNDC5 by $\sim 70 \%$, which was completely reversed by overexpressing TXNDC5; combined treatment with cisplatin $(40 \mu \mathrm{M})$ and cetuximab $(150 \mu \mathrm{g} / \mathrm{ml})$ restored the expression of TXNDC5 to the control level, compared with their individual effect. The expression of CHOP, a decisive factor in ER-stress-associated apoptosis $(21,22)$, was increased by $\sim 2.5$-fold by cisplatin; this effect of cisplatin was more than doubled by TXNDC5 knockdown (Fig. 3). Cetuximab increased the expression of CHOP by $\sim 3$-fold, which was completely eliminated by TXNDC5 overexpression (Fig. 3). Cisplatin and cetuximab demonstrated a 
Table I. TXNDC5 mRNA levels in LSCC cells following treatment with cisplatin.

TXNDC5 mRNA levels at time point, $\mathrm{h}$

\begin{tabular}{rcccc}
\cline { 2 - 5 } Cisplatin, $\mu \mathrm{M}$ & 12 & 24 & 36 & 48 \\
\hline 5 & $1.01 \pm 0.03$ & $1.03 \pm 0.03$ & $1.05 \pm 0.04$ & $1.02 \pm 0.02$ \\
10 & $1.19 \pm 0.06^{\mathrm{a}}$ & $1.55 \pm 0.08^{\mathrm{a}, \mathrm{c}}$ & $1.97 \pm 0.11^{\mathrm{a}, \mathrm{c}, \mathrm{d}}$ & $2.07 \pm 0.12^{\mathrm{a}, \mathrm{c}, \mathrm{d}}$ \\
20 & $1.68 \pm 0.08^{\mathrm{a}, \mathrm{b}}$ & $2.39 \pm 0.13^{\mathrm{a}-\mathrm{c}}$ & $2.94 \pm 0.15^{\mathrm{a}-\mathrm{d}}$ & $3.06 \pm 0.15^{\mathrm{a}-\mathrm{d}}$ \\
40 & $1.76 \pm 0.09^{\mathrm{a}, \mathrm{b}}$ & $2.50 \pm 0.14^{\mathrm{a}-\mathrm{c}}$ & $3.04 \pm 0.15^{\mathrm{a}-\mathrm{d}}$ & $3.19 \pm 0.16^{\mathrm{a}-\mathrm{d}}$ \\
\hline
\end{tabular}

The mRNA levels of TXNDC5 in treated AMC-HN-8 human LSCC cells are presented as fold changes compared with untreated cells (designated as 1$)$. ${ }^{\mathrm{a}}<0.05$ vs. treatment with cisplatin $(5 \mu \mathrm{M})$; ${ }^{\mathrm{b}} \mathrm{P}<0.05$ vs. treatment with cisplatin $(10 \mu \mathrm{M}) ;{ }^{c} \mathrm{P}<0.05$ vs. $12 \mathrm{~h}$ of treatment with cisplatin at each concentration; ${ }^{\mathrm{d}} \mathrm{P}<0.05$ vs. $24 \mathrm{~h}$ of treatment with cisplatin at each concentration. TXNDC5, thioredoxin domain-containing protein 5; LCSS, laryngeal squamous cell carcinoma.

Table II. TXNDC5 mRNA levels in LSCC cells following treatment with cetuximab.

TXNDC5 mRNA levels at times point, $\mathrm{h}$

\begin{tabular}{ccccc}
\cline { 2 - 5 } Cetuximab,$\mu \mathrm{g} / \mathrm{ml}$ & 12 & 24 & 36 & 48 \\
\hline 10 & $1.03 \pm 0.02$ & $1.01 \pm 0.02$ & $0.98 \pm 0.03$ & $0.96 \pm 0.03$ \\
50 & $0.92 \pm 0.03^{\mathrm{a}}$ & $0.76 \pm 0.06^{\mathrm{a}, \mathrm{c}}$ & $0.62 \pm 0.07^{\mathrm{a}, \mathrm{c}, \mathrm{d}}$ & $0.57 \pm 0.07^{\mathrm{a}, \mathrm{c}, \mathrm{d}}$ \\
100 & $0.84 \pm 0.06^{\mathrm{a}, \mathrm{b}}$ & $0.50 \pm 0.08^{\mathrm{a}-\mathrm{c}}$ & $0.38 \pm 0.06^{\mathrm{a}-\mathrm{d}}$ & $0.33 \pm 0.07^{\mathrm{a}-\mathrm{d}}$ \\
150 & $0.79 \pm 0.07^{\mathrm{a}, \mathrm{b}}$ & $0.44 \pm 0.08^{\mathrm{a}-\mathrm{c}}$ & $0.32 \pm 0.07^{\mathrm{a}-\mathrm{d}}$ & $0.27 \pm 0.06^{\mathrm{a}-\mathrm{d}}$
\end{tabular}

The mRNA levels of TXNDC5 in treated AMC-HN-8 human LSCC cells are presented as fold changes compared with untreated cells (designated as 1). ${ }^{\mathrm{a}} \mathrm{P}<0.05 \mathrm{vs}$. treatment with cetuximab $(10 \mu \mathrm{g} / \mathrm{ml}) ;{ }^{b} \mathrm{P}<0.05 \mathrm{vs}$. treatment with cetuximab $(50 \mu \mathrm{g} / \mathrm{ml}) ;{ }^{\mathrm{c}} \mathrm{P}<0.05 \mathrm{vs} .12 \mathrm{~h}$ of treatment with cetuximab at each concentration; ${ }^{\mathrm{d}} \mathrm{P}<0.05$ vs. $24 \mathrm{~h}$ of treatment with cetuximab at each concentration. TXNDC5, thioredoxin domain-containing protein 5; LSCC, laryngeal squamous cell carcinoma.

combinatorial effect on increasing the expression of $\mathrm{CHOP}$ which was decreased by $\sim 45 \%$ by TXNDC5 overexpression. The level of cleaved caspase-3, a major caspase activated in apoptotic cells (29), was increased by $\sim 4$-fold by cisplatin; this effect of cisplatin was increased by $>2$-fold by TXNDC5 knockdown (Fig. 3). Cetuximab increased the level of cleaved caspase-3 by $\sim 3$-fold, which was completely eliminated by TXNDC5 overexpression (Fig. 3). Cisplatin and cetuximab demonstrated a combinatorial effect on increasing the level of cleaved/activated caspase-3, which was decreased by $\sim 50 \%$ by TXNDC5 overexpression. The findings were confirmed by directly measuring the caspase-3 activity (Fig. 4), which demonstrated a similar data trend.

It has been reported that TXNCD5 maintains levels of cellular reductants and that drug- or siRNA-induced downregulation of TXNDC5 induces ROS, which in turn activates ER stress and CHOP expression (30). Therefore, the interactive effects of TXNDC5, cisplatin, cetuximab and ROS scavenger/antagonist NAC on ROS production and $\mathrm{CHOP}$ expression in LSCC cells were investigated. As demonstrated in Fig. 5A, cisplatin $(40 \mu \mathrm{M})$ and cetuximab $(150 \mu \mathrm{g} / \mathrm{ml})$ significantly induced ROS in AMC-HN-8 cells $(\mathrm{P}<0.05)$, which was respectively enhanced by TNXDC5 knockdown and inhibited by TXNDC5 overexpression; cisplatin and cetuximab exhibited a combinatorial effect on inducing ROS, which was significantly eliminated by TXNDC5 overexpression or NAC $(\mathrm{P}<0.05)$. As demonstrated in Fig. 5B, NAC significantly decreased cisplatin- and cetuximab-induced CHOP expression in addition to the combinatorial promoting effect of cisplatin and cetuximab on CHOP expression in AMC-HN-8 cells $(\mathrm{P}<0.05)$.

As demonstrated in Fig. 6, treatment with cisplatin $(40 \mu \mathrm{M})$ for $48 \mathrm{~h}$ resulted in $56 \%$ of apoptosis, which was increased to $82 \%$ by TXNDC5 knockdown and decreased to $43 \%$ by NAC; treatment with cetuximab $(150 \mu \mathrm{g} / \mathrm{ml})$ for $48 \mathrm{~h}$ resulted in $30 \%$ apoptosis, which was brought down to $14.5 \%$ by TXNDC5 and to $21 \%$ by NAC. Combined treatment with cisplatin $(40 \mu \mathrm{M})$ and cetuximab $(150 \mu \mathrm{g} / \mathrm{ml})$ resulted in $76 \%$ apoptosis, which was brought down to $54 \%$ by TXNDC5 overexpression and to $63 \%$ by NAC. Analyses of the data revealed that knockdown of TXNDC5 augmented the apoptotic effect of cisplatin by $\sim 54 \%$ $[(82-56 \%) /(56-7.7 \%)=53.8 \%$; basal apoptosis level $=7.7 \%]$; overexpression of TXNDC5 reduced the apoptotic effect of cetuximab by $\sim 70 \%$ [(30-14.5\%)/(30-7.7\%)=69.5\%]; the effect of TXNDC5 was primarily mediated by inhibiting ROS production $(\sim 59 \%)[(76-63 \%) /(76-54 \%)=59.1 \%]$.

The above findings suggested that cetuximab enhanced the apoptotic effect of cisplatin on LSCC cells by promoting ER 


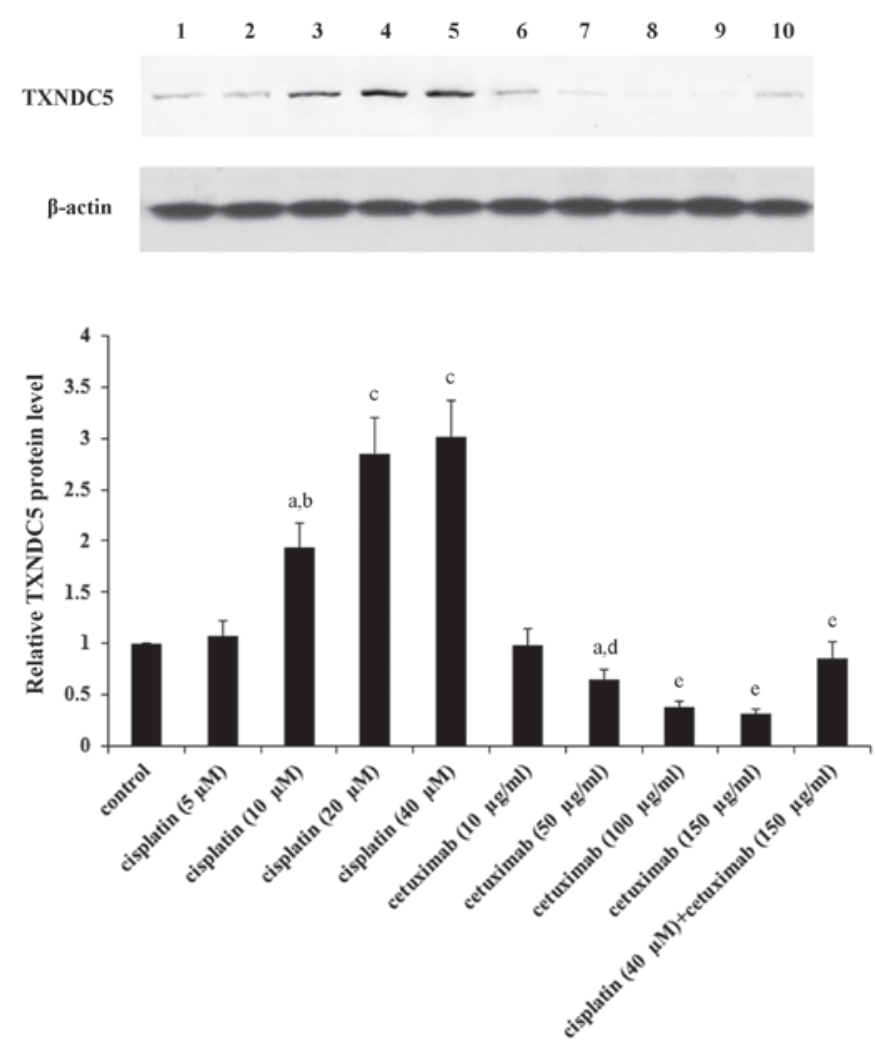

Figure 1. TXNDC5 protein levels in laryngeal squamous cell carcinoma cells in the presence of cisplatin and/or cetuximab. AMC-HN-8 human LSCC cells were treated with cisplatin $(5,10,20$ and $40 \mu \mathrm{M})$ and/or cetuximab $(10,50,100$ and $150 \mu \mathrm{g} / \mathrm{ml})$ for $48 \mathrm{~h}$. Then cell lysates were subject to western blot analysis for TXNDC5 expression. Lysates from untreated AMC-HN-8 cells were used as a control. Lane 1, control; lane 2, cisplatin (5 $\mu \mathrm{M})$; lane 3 , cisplatin $(10 \mu \mathrm{M})$; lane 4 , cisplatin $(20 \mu \mathrm{M})$; lane 5, cisplatin $(40 \mu \mathrm{M})$; lane 6 , cetuximab $(10 \mu \mathrm{g} / \mathrm{ml})$; lane 7 , cetuximab $(50 \mu \mathrm{g} / \mathrm{ml})$; lane 8 , cetuximab $(100 \mu \mathrm{g} / \mathrm{ml})$; lane 9, cetuximab $(150 \mu \mathrm{g} / \mathrm{ml})$; lane 10 , cisplatin $(40 \mu \mathrm{M})+$ cetuximab $(150 \mu \mathrm{g} / \mathrm{ml}) . \beta$-actin was used as a loading control. Density of the TXNDC5 blot was normalized against that of $\beta$-actin to obtain a relative density, which was expressed as fold changes to that of control (designated as 1$)$. ${ }^{a} \mathrm{P}<0.05$ vs. control; ${ }^{\mathrm{b}} \mathrm{P}<0.05$ vs. cisplatin $(5 \mu \mathrm{M})$; ${ }^{\mathrm{c}} \mathrm{P}<0.05$ vs. cisplatin $(10 \mu \mathrm{M}) ;{ }^{\mathrm{d}} \mathrm{P}<0.05$ vs. cetuximab $(10 \mu \mathrm{g} / \mathrm{ml}) ;{ }^{\mathrm{e}} \mathrm{P}<0.05$ vs. cetuximab $(50 \mu \mathrm{g} / \mathrm{ml})$. TXNDC5, thioredoxin domain-containing protein 5 .

stress-associated apoptosis primarily via inhibiting expression of TXNDC5 and thereby increasing ROS production.

Cisplatin and cetuximab exhibit opposing effects on TXNDC5 gene promoter. As indicated in Tables I and II, cisplatin and cetuximab exhibited opposing effects on the TXNDC5 mRNA level, suggesting that the two drugs may affect the TXNDC5 gene promoter activity. AMC-HN-8 cells were transfected with a human TXNDC5 gene promoter/luciferase reporter, and the cells were treated with cisplatin $(5,10,20$ and $40 \mu \mathrm{M})$ or cetuximab $(10,50,100$ and $150 \mu \mathrm{g} / \mathrm{ml})$ for $48 \mathrm{~h}$. As demonstrated in Fig. 7, cisplatin and cetuximab concentration-dependently increased and decreased the TXNDC5 promoter activity, respectively. Combined treatment with cisplatin $(40 \mu \mathrm{M})$ and cetuximab $(150 \mu \mathrm{g} / \mathrm{ml})$ restored the TXNDC5 promoter activity to the control level, compared with their individual effect (Fig. 7). The findings suggested that cisplatin and cetuximab exhibit opposing effects on the TXNDC5 gene promoter.

As TXNDC5 expression is reportedly regulated by the orphan nuclear receptor NR4A1 in cancer cell lines (30-32) and
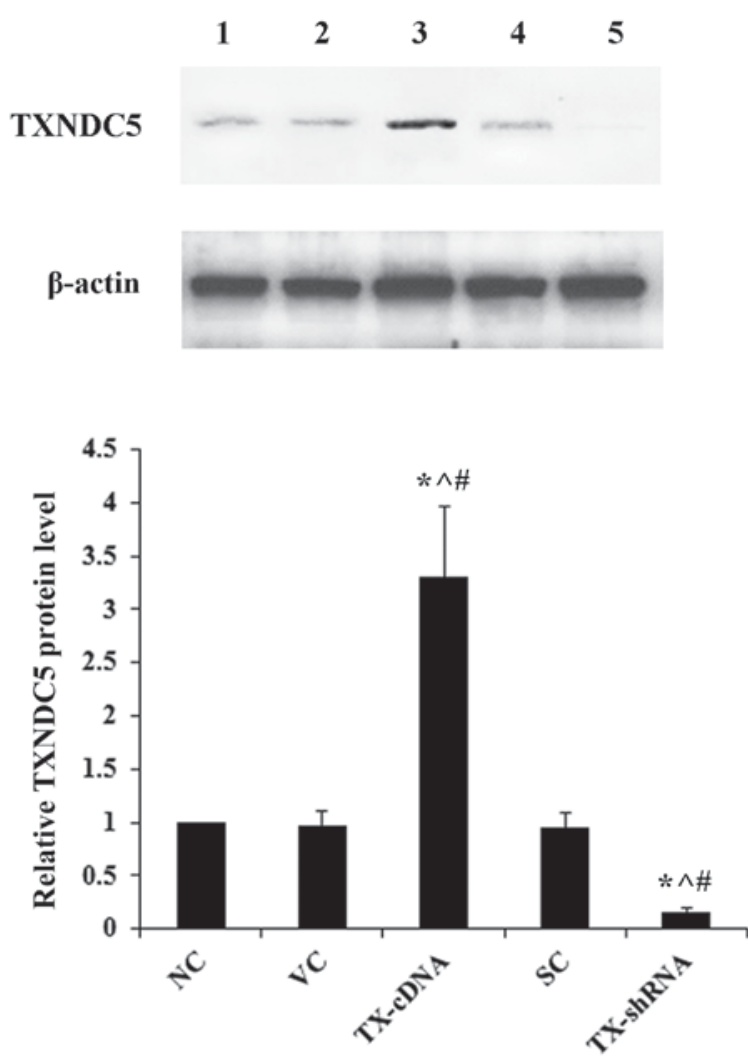

Figure 2. Overexpression and knockdown of TXNDC5 in laryngeal squamous cell carcinoma cells. AMC-HN-8 cells were transfected with a human TXNDC5-cDNA expression vector or transduced with human TXNDC5-shRNA lentiviral particles to overexpress and knock down TXNDC5, respectively. The NC, cells transfected with the VC, or cells transduced with SC were used as controls. Lane 1, NC; lane 2, VC; lane 3, TX-cDNA; lane 4, SC; lane 5, TX-shRNA. $\beta$-actin was used as a loading control. Density of the TXNDC5 blot was normalized against that of $\beta$-actin to obtain a relative density, which was expressed as fold changes to that of $\mathrm{NC}$ (designated as 1 ). ${ }^{*} \mathrm{P}<0.05$ vs. $\mathrm{NC} ;{ }^{\wedge} \mathrm{P}<0.05$ vs. $\mathrm{VC} ;{ }^{\#} \mathrm{P}<0.05$ vs. SC. TXNDC5/TX, thioredoxin domain-containing protein 5; shRNA, short hairpin RNA; NC, untransduced/untransfected cells; VC, empty expression vector; $\mathrm{SH}$, control shRNA lentiviral particles.

NR4A1 also serves a role in cisplatin-induced responses $(33,34)$, it was subsequently examined whether cisplatin and/or cetuximab exhibited an effect on NR4A1 levels in the nucleus of AMC-HN-8 cells. As demonstrated in Fig. 8, cisplatin and cetuximab demonstrated no significant effects on the nuclear NR4A1 protein level, suggesting that NR4A1 did not serve a role in the regulatory effects of cisplatin and cetuximab on the TXNDC5 gene promoter.

\section{Discussion}

Cisplatin and cetuximab have been used for the treatment of LSCC $(5,6)$. It has been demonstrated that cisplatin and inhibition of EGFR signaling may induce ER stress-associated apoptosis (11-16). However, ER protein TXNDC5 reportedly protects cells from ER stress-induced apoptosis $(24,25)$. The present study provided the first evidence, to the best of the authors' knowledge, that: i) While inducing ER stress-associated apoptosis, cisplatin also induces expression of TXNDC5 in LSCC cells; ii) cetuximab inhibits the expression of TXNDC5 in LSCC cells; and iii) cetuximab enhances 

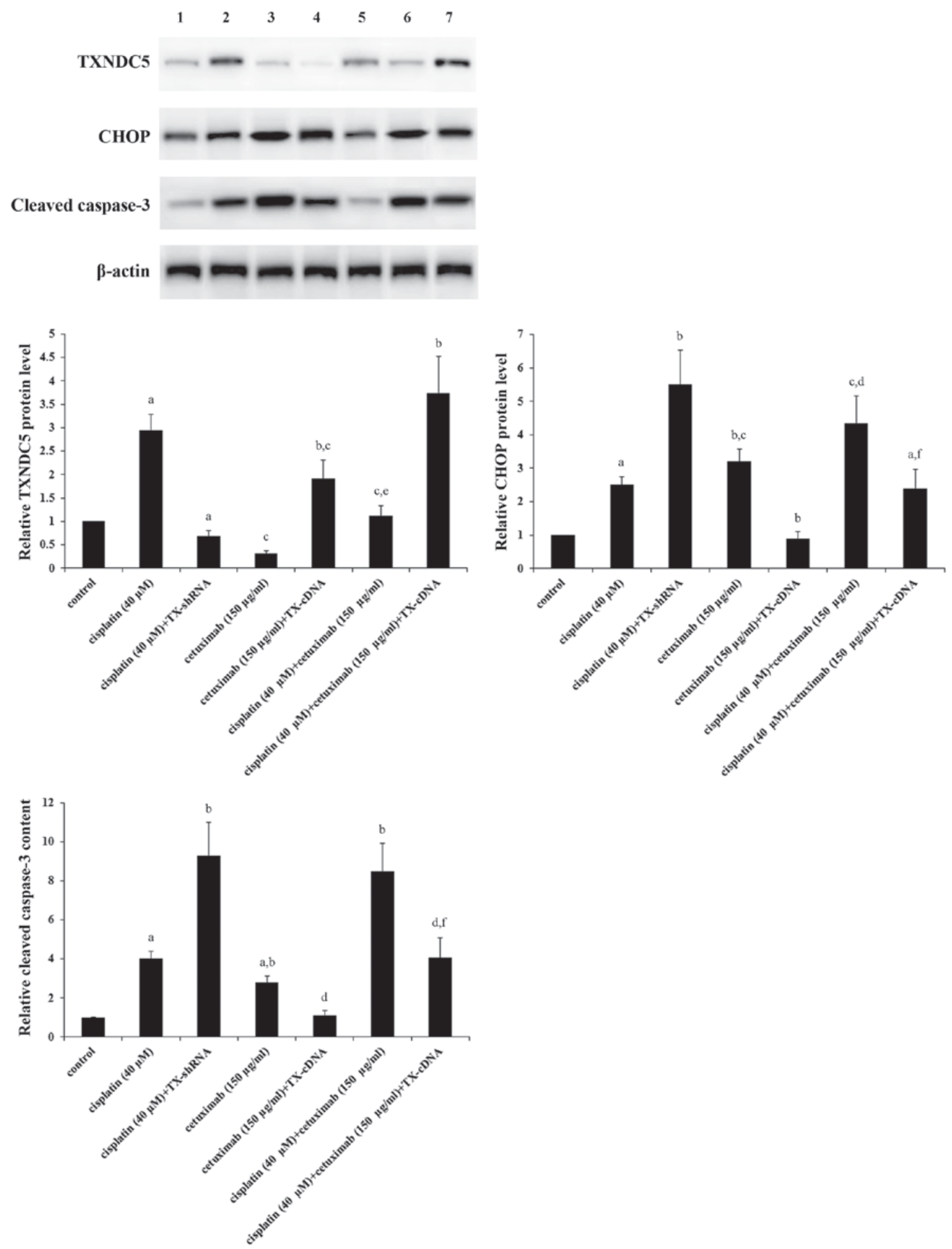

Figure 3. Protein levels of TXNDC5, CHOP and cleaved caspase-3 in laryngeal squamous cell carcinoma cells with or without TXNDC5 overexpression or knockdown in the presence of cisplatin and/or cetuximab. AMC-HN-8 cells with or without TXNDC5 overexpression (TX-cDNA) or knockdown (TX-shRNA) were treated with cisplatin $(40 \mu \mathrm{M})$ and/or cetuximab $(150 \mu \mathrm{g} / \mathrm{ml})$ for $48 \mathrm{~h}$. The cell lysates were subject to western blot analyses to determine the protein levels of TXNDC5, CHOP and cleaved caspase-3. Lysates from untreated AMC-HN-8 cells were used as a control. Lane 1, control; lane 2, cisplatin (40 $\mu$ M); lane 3, cisplatin $(40 \mu \mathrm{M})+\mathrm{TX}$-shRNA; lane 4, cetuximab $(150 \mu \mathrm{g} / \mathrm{ml})$; lane 5, cetuximab $(150 \mu \mathrm{g} / \mathrm{ml})+$ TX-cDNA; lane 6 , cisplatin $(40 \mu \mathrm{M})+$ cetuximab $(150 \mu \mathrm{g} / \mathrm{ml}) ;$ lane 7 , cisplatin $(40 \mu \mathrm{M})+$ cetuximab $(150 \mu \mathrm{g} / \mathrm{ml})+$ TX-cDNA. $\beta$-actin blotting was used as a loading control. Density of the TXNDC5, CHOP or cleaved caspase- 3 blot was respectively normalized against that of $\beta$-actin to obtain a relative density, which was expressed as fold changes to that of control (designated as 1). ${ }^{\mathrm{a}} \mathrm{P}<0.05$ vs. control; ${ }^{\mathrm{b}} \mathrm{P}<0.05$ vs. cisplatin $(40 \mu \mathrm{M}) ;{ }^{\circ} \mathrm{P}<0.05$ vs. cisplatin $(40 \mu \mathrm{M})+\mathrm{TX}$-shRNA; ${ }^{\mathrm{d}} \mathrm{P}<0.05$ vs. cetuximab $(150 \mu \mathrm{g} / \mathrm{ml}) ;{ }^{\mathrm{e}} \mathrm{P}<0.05$ vs. cetuximab $(150 \mu \mathrm{g} / \mathrm{ml})+\mathrm{TX}$-cDNA; ${ }^{\mathrm{f}} \mathrm{P}<0.05 \mathrm{vs}$. cisplatin $(40 \mu \mathrm{M})+$ cetuximab $(150 \mu \mathrm{g} / \mathrm{ml})$. TXNDC5/TX, thioredoxin domain-containing protein 5 ; CHOP, CCAAT/enhancer-binding protein homologous protein; shRNA, short hairpin RNA.

the apoptotic effect of cisplatin on LSCC cells primarily via inhibiting expression of TXNDC5.
As the previously widely used Hep-2 cell line has been identified to be dominated by HeLa cell contamination rather 


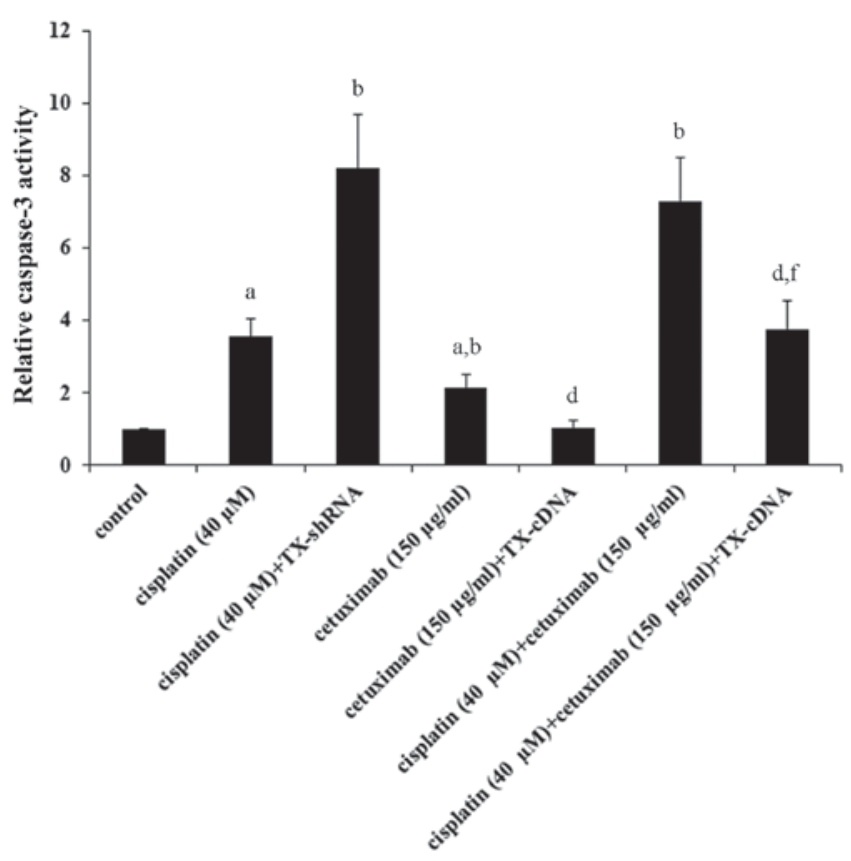

Figure 4. Caspase 3 activities in laryngeal squamous cell carcinoma cells with or without TX overexpression or knockdown in the presence of cisplatin and/or cetuximab. AMC-HN-8 cells with or without TX overexpression (TX-cDNA) or knockdown (TX-shRNA) were treated with cisplatin $(40 \mu \mathrm{M})$ and/or cetuximab $(150 \mu \mathrm{g} / \mathrm{ml})$ for $48 \mathrm{~h}$ and the caspase- 3 activity was measured with a colorimetric caspase 3 assay kit and expressed as fold changes to that of untreated cells (control; designated as 1). ${ }^{\mathrm{a}} \mathrm{P}<0.05$ vs. control; ${ }^{\mathrm{b}} \mathrm{P}<0.05$ vs. cisplatin $(40 \mu \mathrm{M}) ;{ }^{\mathrm{d}} \mathrm{P}<0.05$ vs. cetuximab $(150 \mu \mathrm{g} / \mathrm{ml}) ;{ }^{\mathrm{f}} \mathrm{P}<0.05$ vs. cisplatin $(40 \mu \mathrm{M})+$ cetuximab $(150 \mu \mathrm{g} / \mathrm{ml})$. TX, thioredoxin domain-containing protein 5; shRNA, short hairpin RNA.

than LSCC cells (35), only the AMC-HN-8 human LSCC cell line was used as a cell model in the study (36). In agreement with previous studies demonstrating that cisplatin induces ER stress-associated apoptosis $(14,21)$, cisplatin induced ER stress-associated apoptosis in LSCC cells in the present study, as evidenced by elevated levels of CHOP, caspase activity and apoptosis. Cisplatin also induced TXNDC5, an ER protein protective against ER stress-associated apoptosis (23-26); this may be a protective response of LSCC cells to promote survival under cisplatin-induced ER stress. The direct effect of this response was to decrease cisplatin-induced apoptosis, which was demonstrated by: i) The marked enhancement of the apoptotic effect of cisplatin following TXNDC5 knockdown; and ii) cetuximab, which inhibited the expression of TXNDC5, markedly enhanced the apoptotic effect of cisplatin and this effect was eliminated by overexpressing TXNDC5. Knockdown of TXNDC5 augmented the apoptotic effect of cisplatin by $\sim 54 \%$, suggesting that ER stress-associated apoptosis is a major mechanism underlying the apoptotic effect of cisplatin on LSCC cells and that TXNDC5 is a critical factor in this process.

It has been reported that cetuximab effectively antagonizes EGFR signaling $(5,6,37)$ and that inhibition of EGFR signaling induces ER stress-associated apoptosis $(15,16)$. In agreement with these previous reports, cetuximab induced ER stress-associated apoptosis in LSCC cells in the present study, as evidenced by elevated levels of CHOP, caspase activity and apoptosis. Overexpression of TXNDC5 reduced the apoptotic effect of cetuximab by $\sim 70 \%$, suggesting that ER
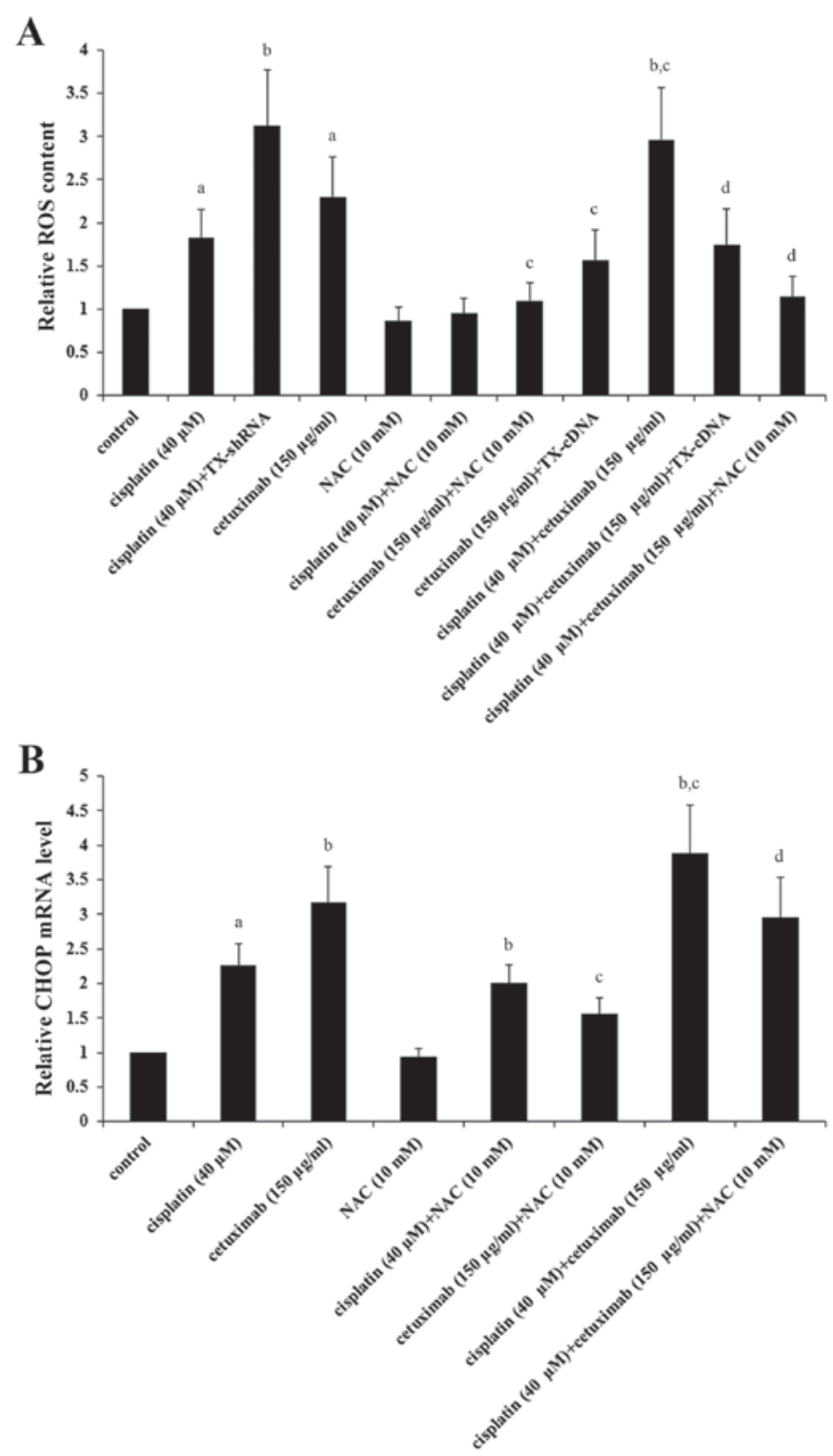

Figure 5. ROS production and CHOP mRNA levels in laryngeal squamous cell carcinoma cells with or without TX overexpression or knockdown in the presence of cisplatin, cetuximab and/or ROS scavenger. AMC-HN-8 cells with or without TX overexpression (TX-cDNA) or knockdown (TX-shRNA) were treated with cisplatin $(40 \mu \mathrm{M})$ and/or cetuximab $(150 \mu \mathrm{g} / \mathrm{ml})$ in the presence or absence of $10 \mu \mathrm{M}$ ROS scavenger NAC for $48 \mathrm{~h}$. (A) ROS production and (B) the CHOP mRNA level were determined and expressed as fold changes to those of untreated cells (control; designated as 1), respectively. ${ }^{\mathrm{a}} \mathrm{P}<0.05$ vs. control; ${ }^{\mathrm{b}} \mathrm{P}<0.05$ vs. cisplatin $(40 \mu \mathrm{M}) ;{ }^{\mathrm{C}} \mathrm{P}<0.05$ vs. cetuximab $(150 \mu \mathrm{g} / \mathrm{ml}) ;{ }^{d} \mathrm{P}<0.05$ vs. cisplatin $(40 \mu \mathrm{M})+$ cetuximab $(150 \mu \mathrm{g} / \mathrm{ml})$. ROS, reactive oxygen species; $\mathrm{CHOP}, \mathrm{CCAAT} / \mathrm{enhancer}^{-b i n d i n g}$ protein homologous protein; TX, thioredoxin domain-containing protein 5; shRNA, short hairpin RNA; NAC, $\mathrm{N}$-acetylcysteine.

stress-associated apoptosis is a major mechanism underlying the apoptotic effect of cetuximab on LSCC cells and that TXNDC5 is a critical factor in this process.

In agreement with previous studies demonstrating that TXNDC5 protects cells from ER stress-induced apoptosis $(24,25)$, the present study demonstrated by overexpression and knockdown experiments that TXNDC5 is an effective protective/survival factor against cisplatin- and cetuximab-induced ER stress-associated apoptosis. Therefore, TXNDC5 may be a new potential therapeutic target for LSCC 


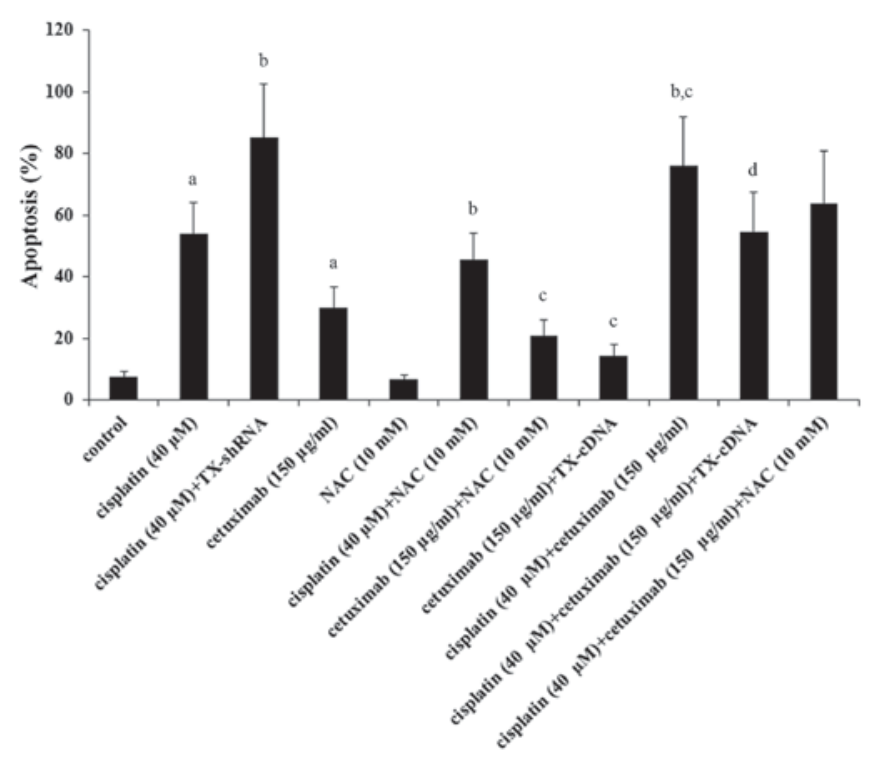

Figure 6. Apoptosis in laryngeal squamous cell carcinoma cells with or without TX overexpression or knockdown in the presence of cisplatin, cetuximab and/or ROS scavenger. AMC-HN-8 cells with or without TX overexpression (TX-cDNA) or knockdown (TX-shRNA) were treated with cisplatin $(40 \mu \mathrm{M})$ and/or cetuximab $(150 \mu \mathrm{g} / \mathrm{ml})$ in the presence or absence of $10 \mathrm{mM}$ ROS scavenger/antagonist NAC for $48 \mathrm{~h}$. The apoptosis rate (in percentage of total cells) was measured with a microplate reader-based apoptosis detection kit. ${ }^{a} \mathrm{P}<0.05$ vs. control; ${ }^{b} \mathrm{P}<0.05$ vs. cisplatin $(40 \mu \mathrm{M})$; ${ }^{\mathrm{c}} \mathrm{P}<0.05$ vs. cetuximab $(150 \mu \mathrm{g} / \mathrm{ml}) ;{ }^{\mathrm{d}} \mathrm{P}<0.05$ vs. cisplatin $(40 \mu \mathrm{M})+$ cetuximab $(150 \mathrm{mg} / \mathrm{ml})$. TX, thioredoxin domain-containing protein 5 ; shRNA short hairpin RNA; NAC, N-acetylcysteine.

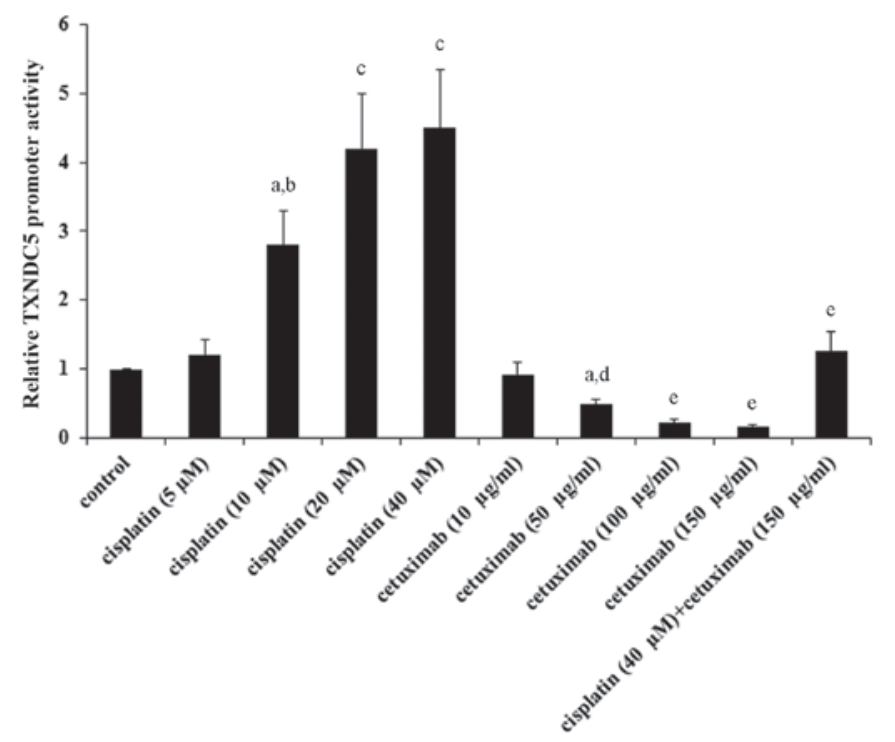

Figure 7. TXNDC5 gene promoter activities in laryngeal squamous cell carcinoma cells in the presence of cisplatin and/or cetuximab. AMC-HN-8 cells were transfected with a human TXNDC5 gene promoter/luciferase reporter for $24 \mathrm{~h}$ and then treated with cisplatin $(5,10,20$ and $40 \mu \mathrm{M})$ and/or cetuximab $(10,50,100$ and $150 \mu \mathrm{g} / \mathrm{ml})$ for $48 \mathrm{~h}$. Luciferase activities were expressed as fold changes to that of untreated cells (control; designated as 1$)$. ${ }^{a} \mathrm{P}<0.05$ vs. control; ${ }^{b} \mathrm{P}<0.05$ vs. cisplatin $(5 \mu \mathrm{M})$; ${ }^{\mathrm{c}} \mathrm{P}<0.05$ vs. cisplatin $(10 \mu \mathrm{M}) ;{ }^{\mathrm{d}} \mathrm{P}<0.05 \mathrm{vs}$. cetuximab $(10 \mu \mathrm{g} / \mathrm{ml}) ;{ }^{\mathrm{e}} \mathrm{P}<0.05$ vs. cetuximab $(50 \mu \mathrm{g} / \mathrm{ml})$. TXNDC5, thioredoxin domain-containing protein 5.

and other cancers. In the present study, cetuximab enhanced the apoptotic effect of cisplatin on LSCC cells primarily by inhibiting the expression of TXNDC5 and the overexpression

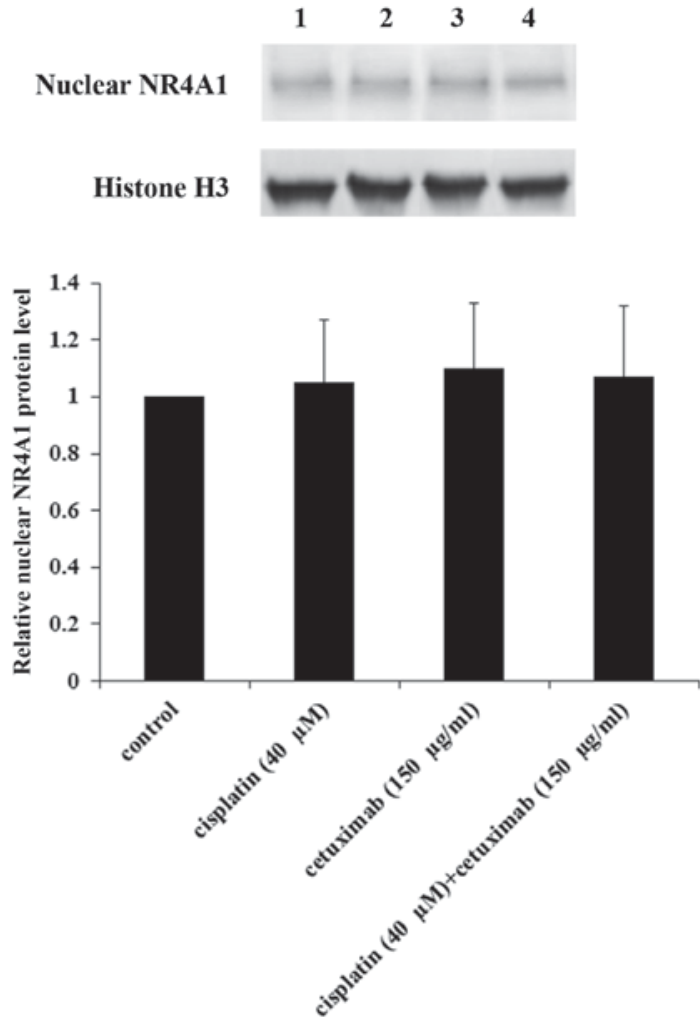

Figure 8. Nuclear NR4A1 protein levels in LSCC cells in the presence of cisplatin and/or cetuximab. AMC-HN-8 human LSCC cells were treated with cisplatin $(40 \mu \mathrm{M})$ and/or cetuximab $(150 \mu \mathrm{g} / \mathrm{ml})$ for $48 \mathrm{~h}$. Then the nuclear extracts were subject to western blot analyses for NR4A1 expression. Lysates from untreated AMC-HN-8 cells were used as a control. Lane 1, control; lane 2, cisplatin $(40 \mu \mathrm{M})$; lane 3 , cetuximab $(150 \mu \mathrm{g} / \mathrm{ml})$; lane 4 , cisplatin $(40 \mu \mathrm{M})+$ cetuximab $(150 \mu \mathrm{g} / \mathrm{ml})$. Nuclear protein histone $\mathrm{H} 3$ blotting was used as a loading control. Density of the nuclear NR4A1 blot was normalized against that of histone $\mathrm{H} 3$ to obtain a relative density, which was expressed as fold changes to that of control (designated as 1). NR4A1, nuclear receptor subfamily 4 group A member 1; LSCC, laryngeal squamous cell carcinoma.

of TXNDC5 eliminated the enhancing effect of cetuximab. It may be worthwhile to examine whether cetuximab in combination with ER stress-inducing chemotherapeutic agents other than cisplatin may benefit patients with LSCC or other cancers. In addition, as radiotherapy is a major treatment for a number of types of cancer, including advanced LSCC (4), and induces ER stress in tumor cells $(38,39)$, cetuximab in combination with radiotherapy may benefit patients with advanced LSCC or other cancer types.

TXNDC5 reportedly facilitates the correct folding of proteins via the formation of disulfide bonds through its thioredoxin domains, thereby alleviating ER stress and protecting cells from ER stress-associated apoptosis (24-26). It has also been demonstrated that TXNCD5 maintains levels of cellular reductants and that drug- or siRNA-induced downregulation of TXNDC5 induces ROS, which in turn activates ER stress and CHOP expression (30). Consistent with previous reports, the present study identified that cisplatin and cetuximab significantly induced ROS and CHOP expression in AMC-HN-8 cells, which were respectively enhanced by TNXDC5 knockdown and inhibited by TXNDC5 overexpression; an ROS scavenger/antagonist significantly decreased cisplatin- and cetuximab-induced ROS and CHOP expression. Apoptosis analysis suggested 
that $59 \%$ of TXNDC5 overexpression-induced inhibition of the apoptotic effect of cetuximab may be attributed to it inhibiting ROS production. The present results suggest that cetuximab enhances cisplatin-induced ER stress-associated apoptosis primarily by regulating TXNDC5-mediated inhibition of ROS production. Nevertheless, the other mechanisms involved in how TXNDC5 functions to lessen cisplatin- and cetuximab-induced ER stress in LSCC cells remain to be elucidated and require future studies. The present study identified that cisplatin and cetuximab exhibited opposing effects on the TXNDC5 gene promoter, suggesting that cisplatin and cetuximab regulate the expression of TXNDC5 at the gene transcription/promoter level. The orphan nuclear receptor NR4A1 reportedly regulates TNXDC5 expression (30-32) and also serves a role in cisplatin-induced responses $(33,34)$. However, as cisplatin and cetuximab demonstrated no significant effects on the nuclear NR4A1 protein level, it is unlikely that NR4A1 mediates the regulatory effects of cisplatin and cetuximab on the TXNDC5 gene promoter. It is hypothesized that the mechanisms underlying transcriptional regulation of TXNDC5 expression may be investigated in future studies.

In conclusion, the results of the present study suggested that ER stress-associated apoptosis is a major mechanism underlying the apoptotic effect of cisplatin and cetuximab on LSCC cells. Cetuximab enhances cisplatin-induced ER stress-associated apoptosis in LSCC cells primarily by inhibiting the expression of TXNDC5 and thereby increasing ROS production. Cisplatin and cetuximab exhibited stimulatory and inhibitory effects on the TXNDC5 gene promoter, respectively. The present study presented a novel understanding of the pharmacological effects of cisplatin and cetuximab on LSCC. The present study also suggested that TXNDC5 may be a potential novel therapeutic target for LSCC.

\section{Acknowledgements}

The present study was funded by the Science and Technology Foundation of Hunan Province, China (grant no. 2015AK2056).

\section{References}

1. Jemal A, Siegel R, Ward E, Hao Y, Xu J and Thun MJ: Cancer statistics, 2009. CA Cancer J Clin 59: 225-249, 2009.

2. Mnejja M, Hammami B, Bougacha L, Chakroun A, Charfeddine I, Khabir A, Boudaoura T and Ghorbel A: Occult lymph node metastasis in laryngeal squamous cell carcinoma: Therapeutic and prognostic impact. Eur Ann Otorhinolaryngol Head Neck Dis 127: 173-176, 2010.

3. Amar A, Chedid HM, Franzi SA and Rapoport A: Diagnostic and therapeutic delay in patients with larynx cancer at a reference public hospital. Braz J Otorhinolaryngol 76: 700-703, 2010.

4. Hitt R, López-Pousa A, Martinez-Trufero J, Escrig V, Carles J, Rizo A, Isla D, Vega ME, Marti JL, Lobo F, et al: Phase III study comparing cisplatin plus fluorouracil to paclitaxel, cisplatin, and fluorouracil induction chemotherapy followed by chemoradiotherapy in locally advanced head and neck cancer. J Clin Oncol 23: 8636-8645, 2005.

5. Bussu F, Pozzoli G, Giglia V, Rizzo D, Limongelli A, De Corso E, Graziani C, Paludetti G, Navarra P and Almadori G: Effects of the administration of epidermal growth factor receptor specific inhibitor cetuximab, alone and in combination with cisplatin on proliferation and apoptosis of Hep-2 laryngeal cancer cells. J Laryngol Otol 128: 902-908, 2014.
6. Burtness B, Goldwasser MA, Flood W, Mattar B and Forastiere AA; Eastern Cooperative Oncology Group: Phase III randomized trial of cisplatin plus placebo compared with cisplatin plus cetuximab in metastatic/recurrent head and neck cancer: An Eastern Cooperative Oncology Group study. J Clin Oncol 23: 8646-8654, 2005.

7. Lv X, Song DM, Niu YH and Wang BS: Inhibition of heme oxygenase-1 enhances the chemosensitivity of laryngeal squamous cell cancer Hep-2 cells to cisplatin. Apoptosis 21: 489-501, 2016.

8. Macciò A and Madeddu C: Cisplatin: An old drug with a newfound efficacy - from mechanisms of action to cytotoxicity. Expert Opin Pharmacother 14: 1839-1857, 2013.

9. Sancho-Martínez SM, Prieto-García L, Prieto M, López-Novoa JM and López-Hernández FJ: Subcellular targets of cisplatin cytotoxicity: An integrated view. Pharmacol Ther 136: 35-55, 2012.

10. Yu F, Megyesi J and Price PM: Cytoplasmic initiation of cisplatin cytotoxicity. Am J Physiol Renal Physiol 295: F44-F52, 2008

11. Peyrou M, Hanna PE and Cribb AE: Cisplatin, gentamicin, and p-aminophenol induce markers of endoplasmic reticulum stress in the rat kidneys. Toxicol Sci 99: 346-353, 2007.

12. Mandic A, Hansson J, Linder S and Shoshan MC: Cisplatin induces endoplasmic reticulum stress and nucleus-independent apoptotic signaling. J Biol Chem 278: 9100-9106, 2003.

13. Liu H and Baliga R: Endoplasmic reticulum stress-associated caspase 12 mediates cisplatin-induced LLC-PK1 cell apoptosis. J Am Soc Nephrol 16: 1985-1992, 2005

14. Xu Y, Wang C and Li Z: A new strategy of promoting cisplatin chemotherapeutic efficiency by targeting endoplasmic reticulum stress. Mol Clin Oncol 2: 3-7, 2014.

15. Miao Y, Bi XY, Zhao M, Jiang HK, Liu JJ, Li DL, Yu XJ, Yang YH, Huang N and Zang WJ: Acetylcholine inhibits tumor necrosis factor $\alpha$ activated endoplasmic reticulum apoptotic pathway via EGFR-PI3K signaling in cardiomyocytes. J Cell Physiol 230: 767-774, 2015.

16. Hong S, Gu Y, Gao Z, Guo L, Guo W, Wu X, Shen Y, Sun Y, Wu X and Xu Q: EGFR inhibitor-driven endoplasmic reticulum stress-mediated injury on intestinal epithelial cells. Life Sci 119: 28-33, 2014

17. Walter P and Ron D: The unfolded protein response: From stress pathway to homeostatic regulation. Science 334: 1081-1086, 2011.

18. Berridge MJ: The endoplasmic reticulum: A multifunctional signaling organelle. Cell Calcium 32: 235-249, 2002.

19. Jørgensen MM, Bross P and Gregersen N: Protein quality control in the endoplasmic reticulum. APMIS Suppl: 86-91, 2003.

20. Xu Y, Li D, Zeng L, Wang C, Zhang L, Wang Y, Yu Y, Liu S and Li Z: Proteasome inhibitor lactacystin enhances cisplatin cytotoxicity by increasing endoplasmic reticulum stress-associated apoptosis in HeLa cells. Mol Med Rep 11: 189-195, 2015.

21. Zhang R, Wang R, Chen Q and Chang H: Inhibition of autophagy using 3-methyladenine increases cisplatin-induced apoptosis by increasing endoplasmic reticulum stress in U251 human glioma cells. Mol Med Rep 12: 1727-1732, 2015.

22. Nishitoh H: CHOP is a multifunctional transcription factor in the ER stress response. J Biochem 151: 217-219, 2012.

23. Horna-Terrón E, Pradilla-Dieste A, Sánchez-de-Diego C and Osada J: TXNDC5, a newly discovered disulfide isomerase with a key role in cell physiology and pathology. Int J Mol Sci 15: 23501-23518, 2014

24. Sullivan DC, Huminiecki L, Moore JW, Boyle JJ, Poulsom R, Creamer D, Barker J and Bicknell R: EndoPDI, a novel protein-disulfide isomerase-like protein that is preferentially expressed in endothelial cells acts as a stress survival factor. J Biol Chem 278: 47079-47088, 2003.

25. Funkner A, Parthier C, Schutkowski M, Zerweck J, Lilie H, Gyrych N, Fischer G, Stubbs MT and Ferrari DM: Peptide binding by catalytic domains of the protein disulfide isomerase-related protein ERp46. J Mol Biol 425: 1340-1362, 2013.

26. Kojima R, Okumura M, Masui S, Kanemura S, Inoue M, Saiki M, Yamaguchi H, Hikima T, Suzuki M, Akiyama S and Inaba K: Radically different thioredoxin domain arrangement of ERp46, an efficient disulfide bond introducer of the mammalian PDI family. Structure 22: 431-443, 2014.

27. Livak KJ and Schmittgen TD: Analysis of relative gene expression data using real-time quantitative PCR and the 2(-Delta Delta C(T)) method. Methods 25: 402-408, 2001.

28. Johnson DR, Levanat S and Bale AE: Direct molecular analysis of archival tumor tissue for loss of heterozygosity. Biotechniques 19: 190-192, 1995. 
29. Woo M, Hakem R, Soengas MS, Duncan GS Shahinian A, Kägi D, Hakem A, McCurrach M, Khoo W, Kaufman SA, et al: Essential contribution of caspase 3/CPP32 to apoptosis and its associated nuclear changes. Genes Dev 12: 806-819, 1998

30. Lee SO, Jin UH, Kang JH, Kim SB, Guthrie AS, Sreevalsan S, Lee JS and Safe S: The orphan nuclear receptor NR4A1 (Nur77) regulates oxidative and endoplasmic reticulum stress in pancreatic cancer cells. Mol Cancer Res 12: 527-538, 2014.

31. Hedrick E, Lee SO, Doddapaneni R, Singh M and Safe S: Nuclear receptor 4A1 as a drug target for breast cancer chemotherapy. Endocr Relat Cancer 22: 831-840, 2015.

32. Hedrick E, Lee SO, Kim G, Abdelrahim M, Jin UH, Safe S and Abudayyeh A: Nuclear receptor 4A1 (NR4A1) as a drug target for renal cell adenocarcinoma. PLoS One 10: e0128308, 2015.

33. Yao LM, He JP, Chen HZ, Wang Y, Wang WJ, Wu R, Yu CD and Wu Q: Orphan receptor TR3 participates in cisplatin-induced apoptosis via Chk2 phosphorylation to repress intestinal tumorigenesis. Carcinogenesis 33: 301-311, 2012.
34. Lin H, Lin Q, Liu M, Lin Y, Wang X, Chen H, Xia Z, Lu B, Ding F, Wu Q and Wang HR: PKA/Smurf1 signaling-mediated stabilization of Nur77 is required for anticancer drug cisplatin-induced apoptosis. Oncogene 33: 1629-1639, 2014.

35. ATCC. http://atcc.org/Products/All/CCL-23.aspx\# characteristics. Accessed July 1, 2016.

36. Xu L, Chen Z, Xue F, Chen W, Ma R, Cheng S and Cui P: MicroRNA-24 inhibits growth, induces apoptosis, and reverses radioresistance in laryngeal squamous cell carcinoma by targeting X-linked inhibitor of apoptosis protein. Cancer Cell Int 15: 61, 2015.

37. Mendelsohn J and Baselga J: The EGF receptor family as targets for cancer therapy. Oncogene 19: 6550-6565, 2000.

38. Saglar E, Unlu S, Babalioglu I, Gokce SC and Mergen H: Assessment of ER Stress and autophagy induced by ionizing radiation in both radiotherapy patients and ex vivo irradiated samples. J Biochem Mol Toxicol 28: 413-417, 2014.

39. Zhu H, Abulimiti M, Liu H, Su XJ, Liu CH and Pei HP: RITA enhances irradiation-induced apoptosis in p53-defective cervical cancer cells via upregulation of IRE1 $\alpha / X B P 1$ signaling. Oncol Rep 34: 1279-1288, 2015. 